perjudican a veces a otras virtudes, más modestas, del conocimiento. El éxito de la obra de Duhamel-estoy comentando un ejemplar de los setenta $u$ ochenta mil que en estos momentos circulan-y la honestidad indiscutible de sus intereses humanos dan a tales afirmaciones un significado y una fuerza informativa de primer orden. Frente al Baedecker que Paul Morand ha escrito acerca de Nueva York, las invectivas de Georges Duhamel adquieren una coherencia y un sentido de responsabilidad admirables. Justas o injustas-casi siempre unilaterales-son el producto de un orden muy claro del pensamiento europeo. Se instalan todavía-a pesar de sus aciertos literarios-en la categoría política de esa defensa de Occidente a la que Henri Massis consagró hace algunos años uno de sus esfuerzos más tendenciosos. Y, desde este punto de vista, aclaran todo un sector contemporáneo de la existencia francesa.- J A I E T OR R S B ODE T.

Exclusivo para Atenea en Chile.

\title{
ROSAS Y LA POSTERIDAD
}

IIA

actualidad de Rosas en el escenario político argentino es innegable; sobre todo por razón de cierto paralelismo nacionalista que le encuentran algunos con el derrocado presidente Irigoyen. Dos nuevos libros colocan otra vez el aspecto del célebre tirano ante la atención de los historiadores; el de Dardo Corvalán Mendilaharsu y el espléndido ensayo de interpretación de Carlos lbarguren (1).

Corvalán Mendilaharsu ha reunido diez artículos, con pretensiones de ensayo y de un valor desigual. Como escritor es mediocre y como intención histórica alienta en su obra el propósito de revisar un caso histórico en que el factor sentimental actú́ tanto o más que el histórico o científico. En el último tiempo ha soplado un viento favorable a la memoria de don Juan Manuel. No ha sido la menor de las causas revisionistas el intento de ciertos escritores de allegar factores que justifiquen las dictaduras criollistas. En 1915, Estanislao Zeballos decía:

(1) Rosas, por Dardo Corvalán Mendilaharsu. (M. Gleizer, editor. Buenos Aires, 1929.) Juan Manuel de Rosas. Su vida, su tiempo, su drama, por Carlos Ibarguren. (Roldán, editor. Buenos Aires 1930.) 
Hace un cuarto de siglo no era posible hablar científicamente de don Juan Manuel de Rosas. Los últimos actores de la horrible tragedia estaban vivos. La crónica de los tiempos asumía la forma pintoresca y vehemente de la tertulia doméstica... En tal ambiente no se hablaba de Rosas y de sus hombres, sino para maldecirlos, y toda investigación histórica sujeta a método científico era indiscreta y a veces temeraria.

Desde que formul6 ese concepto Zeballos, la historia argentina ha ido serenando su juicio sobre el gran caudillo. Se han reivindicado su valor nacionalista, su sentido de la tierra, su honradez patricia; pero, al mismo tiempo, se solidifica el proceso de su acción negativa. Corvalán Mendilaharsu sólo consigue trazar aspectos sumarios de la compleja silueta. Sus datos son periodísticos, sin enjundia. Su argumentación flaquea y sólo tiene interés por cierto carácter documental. Carlos Ibarguren, en cambio, ofrece un cuadro acabado de la época que sólo tiene parecido con el libro de José María Ramos Mejía: Rosas y su tiempo.

Rosas nació en una casona patricia y heredó de sus antepasados un carácter voluntarioso y dominador. De pequeño para resarcirse de un castigo infligido por sus padres, desembaldosó una habitación en que lo dejaron recluído. Desde su edad juvenil empezó a impregnarse de la pampa. Esta ha de darle un sello personalísimo, a la vez que le imprime una fisonomía criolla perdurable. El ambiente en que se desenvuelve don Juan Manuel está muy bien pintado por Ibarguren:

Gritos guturales, latigazos e interjecciones para azuzar las yuntas, chirridos de ruedas, tintineos de cencerros de yeguas madrinas, mujidos de vacas ariscas, áspero chillar de teros, graznar de chajás y relinchar de baguales. La llanura yerma se dilataba infinita bajo el sol, sin reparo ni sombra alguna, a trechos húmeda y verde, a trechos polvorosa y parda, mientras el convoy avanzaba despacio entre un mar de pastos, de cardizales, de pajonales, o se encajaba en el fango de los pantanos y de las lagunas. Olor de pampa: de trébol y de menta, de hinojo, altamisa y duraznillo, de cañadón y de estiércol, traía el soplo fresco del viento que, libre como las manadas de potros, corría rizando las hierbas.

Este ámbito esculpe en el futuro dominador de la Argentina un sentido ruralista que lo aleja de los unitarios, hombres ciudadanos y afinados por lecturas. Entre el tibio liberalismo de los unitarios, educados en el cultivo de las letras francesas $\mathrm{y}$ de la escuela liberal inglesa, y este hombre primario e instintivo, existe un abismo. Rosas ama las tradiciones pamperas; se cría en el contacto bizarro con indios y lenguaraces. Los gauchos lo aman porque conoce sus secretos e instintos. Se alimenta con fuentadas de mazamorra y de locros. La fuerza 
y la rapidez son sus símbolos. Nada más exótico, para él, que las tertulias unitarias y sus conversaciones lánguidas sobre temas de Europa.

Así surge un hombre de acción, pronto para ejecutar y dominar a las masas con un instinto certero de su fragilidad. Explota el lado débil de éstas y conoce la facilidad mulata para la adulación. Así se levantan sus "gentes de color", sus batallones de cívicos, que recuerdan a los del Ministro Portales. Cuenta W. H. Hudson en su novela El Ombú:

Cuando los gauchos se afiliaron a Rosas y le ayudaron a subir al poder, se hicieron la ilusión de que él era uno de ellos mismos y les daría aquella perfecta libertad para vivir sus vidas a su propio modo, que es su único deseo. Descubrieron su error cuando era demasiado tarde (1).

Rosas, al revés de otros caudillos y gobernantes, creía en la fuerza social de la religión, que supo utilizar en provecho de sus fines políticos. Mientras empiezan a enfriarse sus relaciones con Dorrego, con fino sentido de la realidad advierte el peligro que representaba para él un triunfo de los unitarios. Los llama "agiotistas", que forman una "clase mercantil» y una aristocracia opuesta a sus amigos: los pobres, y a los estancieros, "que eran buenos federales». Cuando el Almirante Brown le dirige una carta en que habla del pronunciamiento de "la clase distinguida» de Buenos Aires, Rosas no contesta la misiva por afecto al viejo marino. En tanto, piensa que esa "clase distinguida» es una oligarquía aristocrática que dirige una logia criminal, amenazadora del orden, tal como lo entiende en su fórmula criolla.

Ya se destaca, pues, el escenario de futuras luchas políticas. Por un lado, una clase cultà y extranjerizante, que desea gozar una vida refinada y viajar; y, por el otro, una oligarquía populista y militar, con sólido arraigo en las clases bajas y en el gaucherío. Rosas consiguió cierta popularidad, que el tiempo desmorona; pero en su primera época disfruta de la amistad del "pobrerío". El espíritu anti-extranjero y, sobre todo, anti-francés halla en Rosas a un magnífico director. Al grito de mueran los extranjeros sarnosos, el gauchaje dió cuenta de las estancias, embargadas o no, de los extranjeros. Observa Ramos Mejía:

El joven químico francés don Antonio Cambacerès, traído de París por don Juan Larrea, crea la verdadera industria del saladero, pero suprime la alegría y los peligros de elas matanzass, en las cuales la destreza de la peonada y las vicisitudes de la singular función atraían al gauchaje aventurero; sus-

(1) W. H. Hudson, El Ombrí, pág. 96. 
tituye el brazo del campesino por el torno sencillo'; quita al lazo sus encantos, al criollo por medio de la máquina su importancia capital, por más que el silencio de la faena y la economía realizada hacen de esa industria y con menos capital, un negocio multiplicador de las utilidades (1).

La superstición acompaña a estas ideas del criollo. Se ven brujerías en muchos experimentos progresistas y en el uso de máquinas que se desconocen. El clero retrasado y colonialista combate al unitarismo y ve en Rosas a un sustentáculo providencial de su predominio. Doña Encarnación Ezcurra, mujer del Dictador, prepara su segundo y definitivo advenimiento al poder por medio de una hábil política de atracción. Ejercía la táctica jesuítica de la seducción. Rosas cuida mucho de atraer al clero.

Dile a mi comadre-le escribe a don Juan M. Terrero-que no afloje a los anarquistas enemigos del sosiego público, que muera antes, porque morir por el orden y la libertad es muerte dulce. Que me le haga una visita al curita nuestro amigo, otra a Farías con encargo de que a mi nombre visite a Navarrete, Visillac, Villegas, etc. (todos ellos jefes y oficiales conspiradores), y a los paisanos amantes de la tranquilidad de la tierra. Otra a mi padrino pidiéndole su santísima bendición. Otra al padre Revige a quien mando incienso, otra al fraile Somellera, cura de la Residencia, encargándole que a mi nombre le haga una visita al Obispo y que bendiga a mi ahijado... Te he estimado las noticias que me das de la opinión pública y que todos los hombres sanos están por la causa de la justicia. Todo lo que pasa es obra de Dios que está visto que nos quiere mucho. Al fraile Canónigo Vidal es preciso perseguirlo, es un facineroso que tiene gran parte en las desgracias presentes..

En el fondo del drama argentino de esa época latía el odio social. Por un lado, el unitario, con modales pomposos y cultos al decir de Sarmiento; y por otro, el federal, imbuído de la ideas viejas criollistas.

En la campaña y en las provincias-dice Ibarguren-se levanta, en oposició. a la política de Buenos Aires, el partido popular que sostiene la bandera republicana y la autonomía local, con los federales.

En el libro de Ibarguren aparecen curiosas referencias a José Miguel Carrera. Ninguna le es favorable. El propio Rosas lo condena con dureza. En la pág. 81 dice:

Las tropas del gobernador santafecino López vencen a Soler y amenazan a Buenos Aires, conjuntamente con la legión de salvajes aventureros de José Miguel Carrera y de Alvear.

(1) Ramos Mejía, Rosas y su tiempo, Tomo I, pág. 165.

(2) Papeles de Rosas, compilados por A. Saldías, Tomo I. 
Rosas dice de Carrera «que tenía ruines designios». (Pág. 96.) Más adelante se habla de una correría de Carrera en esta forma:

Han llevado trescientas personas entre mujeres, criaturas, etc., sacándolas de la iglesia, robando todos los vasos sagrados, sin respetar el copón con las formas consagradas, ni dejarles cómo pitar un cigarro en todo el pueblo, incendiando muchas casas.

Es curioso anotar cómo dos hombres discutidos y vehementes aparecen mezclándose en las páginas de este apasionante libro.

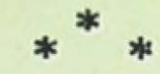

Ibarguren analiza a Rosas desde su juventud hasta su muerte. En el gran cuadro se destacan las notas sombrías de su carácter; pero también se revelan sus condiciones extraordinarias y su sagaz instinto criollo, que lo hace aparecer como una de las más gallardas estampas de América. En una página admirable lo parangona con Facundo:

Exuberante y arrebatado Facundo, cauteloso y reflexivo Rosas; abierto y sensible a la generosidad el uno, cerrado y más obediente al cálculo que a la corazonada el otro; agresivo en la lucha y rectilíneo en sus planes aquél, defensivo y simulador éste, ambos fueron expresiones genuinas de nuestras campañas. Facundo, agreste e hirsuto, trasuntaba aspereza en su físico stan peludo como las patas de un oso'. Rosas, terco y rasurado, aparecía con su severo perfil romano como la imagen impasible de una medalla antigua.

En los ojos renegridos de Facundo ardía el fuego que abrasa los arenales y seca los montes riojanos; en las pupilas cambiantes, ora azuladas, ora glaucas de Rosas vefase solamente, como en el mar profundo, la superficie quieta y fría que oculta la agitación interior.

Una afinidad existía, sin embargo, entre esos temperamentos tan antitéticos: ambos profesaban, como intérpretes del alma campesina, el mismo sentimiento de protesta contra la dominación de la ciudad ejercida por los unitarios y por la política de Rivadavia.

El germen del personalismo argentino destella en esas líneas. Toda la historia de las masas políticas de la nación vecina gravita en ese fenómeno que se reitera después de un siglo. El sentido criollo, socarrón y desconfiado, recela todavía de la metropoli, centro de cultura afinadamente europea. Se necesita un hombre símbolo, un hombre taimado como dice Keyserling. Este representa el deseo de protesta y de reacción criolla que desconfía. La característica del gaucho es esa, máxime en el tiempo en que se forma la República. Rosas, al ascender al poder, resumió su política en un sencillo ideario: Escar- 
miento al enemigo y ostentosa sumisión al partido federal. Sin embargo, Rosas, que toda su vida manifiesta terror a la anarquía y sumisión a la autoridad, sabe usar del desorden y del saqueo cuando es necesario a sus propósitos de dominio.

La revolución de los restauradores, en su aspecto social-dice Ibarguren-, fué el lanzamiento tumultuoso de las turbas de la ciudad y de los gauchos de la campaña, instigados y apoyados por Rosas, contra la burguesía y la clase dirigente porteña que sostenía a las autoridades legales. Rosas por primera y única vez en su vida se apartaba de su norma de sostener el orden, para fomentar la rebelión. El respeto al gobierno y al principio de autoridad desapareció para ser reemplazado por la demagogia turbulenta, que sólo obedecía a la voz del caudillo. (P. 284.)

Junto con ascender definitivamente al poder Rosas, se extiende en toda la Argentina el círculo de hierro del terrorismo. La Sociedad Popular Restauradora, que celebra el triunfo en la de Octubre y persigue a los "salvajes unitarios» se constituye «firme columna del orden y la libertad». Esteperíodo de terrorismo y de ciegas venganzas crea en torno del Tirano una atmósfera de miedo y simulación en la que los psicólogos han visto muchas de las causas que hacen perdurar las dictaduras en América

A los diez años de tiranía-dice Ramos Mejía-, casi toda una generación, que por una razón o por otra había permanecido en la ciudad disciplinada, acabó por claudicar, agobiada casi físicamente por una senilidad precoz. Así se explica que en sus veinte años de opresión no hubiese un brazo armado en contra suya, una sola voluntad que animara la agresión libertadora contra aquel hombre que dormía con las puertas abiertas y sin ninguna vigilancia. $Y$ en otra parte: $E l$ hábito sensitivo de la obediencia los había inutilizado, y por eso se nota este fenómeno sugestivo de psicología colectiva e individual que ninguno de ellos tuvo actuación gubernativa o intelectual después de Caseros hasta hoy. Se habían atrofiado en la inacción; la obediencia y el miedo les había muerto el don de la iniciativa y del pensamiento. (Ramos Mejía, Rosas y su tiempo, Tomo I., p. 355.)

Rosas se estrena destituyendo en masa oficiales como lo hizo en Chile el primer Ministro de Prieto. Más de ciento cincuenta fueron expulsados del Ejército. La desconfianza reinaba sobre los cuarteles y varios militares son fusilados. Rosas se cree dirigido por la Providencia y dice en un discurso vehemente: «El Todopoderoso dirigirá nuestros pasos.» Como rasgos típicos de Rosas pueden anotarse su americanismo, su nacionalismo y su endiosamiento. San Martín, con antelación, comprende que el estado anárquico por que pasaba la Argentina hacía inevitable el advenimiento de un dictador. Las pro- 
vincias, anarquizadas por los caudillos criollos, se rebelaban contra la capital. Se recelaba de su progreso y de las ideas civilizadoras que dominaban en ella. Lo que, en otras circunstancias, habría sido necesario, se hizo orgánico y sistemático. Rosas pasa a ser un tirano trascendente, que mantiene la unidad nacional y su independencia como hizo más tarde $\mathrm{Ci}$ priano Castro en Venezuela.

¿Cómo y por qué nace la tiranía?-se pregunta Ibarguren-.Ella es siempre consecuencia de la anarquía: si ésta es puramente superficial, aquélla es ocasional; pero si el desconcierto es profundo, la tiranía es trascendental. Este último caso se produce cuando la sociedad se encuentra al final de un proceso de descomposición, o cuando se halla en el momento que sigue a un estallido revolucionario. Las tiranías trascendentales representan, pues, en la historia, sea la etapa postrera de la descomposición de una sociedad, o sea la inicial de una era violenta de transformación. Las decadencias terminan y las revoluciones comienzan con tiranías. Toda destrucción de un orden social, ya provenga de la descomposición por decadencia o del derrumbamiento por revolución, engendra el caos. (Pág. 318.)

\section{Rosas esgrimió principios férreos contra el adversario.}

Es preciso no contentarse-dice-con hombres ni con servicios a medias y consagrar el principio de que está contra nosotros el que no está del todo con nosotros.

Revisaba todo lo que se escribía sobre él y corregía, a veces, los originales, enmendando aquello que no estimaba correcto. Una vez se le propone cambiar la palabra esclarecido por la de benemérito. El tirano escribe de su puño y letra: "conforme con benemérito". Rosas, al revés de otros dictadores, tuvo la convicción de que su poderío se debilitaba. Cuando llegaron las vísperas de su caída, reune a los jefes adictos y les propone su eliminación para salvar así su persona y su dignidad. Se le reitera la adhesión; pero ya estaba minado el compacto frente que opuso a los unitarios por muchos años.

Sus últimos días en Inglaterra los describe muy bien Ibarguren. Casi todo el tiempo recela de perder sus papeles, que constituyen una de sus preocupaciones capitales. Los conserva con amor y pensando siempre en escribir un libro que repare su memoria. Vive con ese ideal hasta su muerte. Eso ha permitido conservar a la posteridad un caudal rico de noticias y datos de su período.

La posteridad empieza hoy a juzgar a Rosas con criterihistórico. El libro de Ibarguren revela madurez e imparcialidad. Corvalán Mendilaharsu anuncia otra obra completa sobre esta época azarosa. Es de esperar que la nutran el interés y la 
documentación definitiva que faltan en su reciente colección de artículos. Hasta aquí se habían nutrido los historiadores con la profusa literatura adversa a Rosas: Alberdi, Rivera Indarte, Mármol, Sarmiento, Saldías y Ramos Mejía. Libros como el de Ibarguren señalan una orientación más definitiva sobre el Tirano, cuyos claro-obscuros y cuya barbarie gaucha no le restan grandeza. Es un precursor de modernos tipos de dictadores nacionalistas como Cipriano Castro y de presidentes personalistas como Irigoyen. De ahí su eterno interés, su actualidad vivísima y su originalidad dentro del drama americano.- R I C A R D O A. L A T C H A $M$.

\section{OTROS ASPECTOS DE GOETHE}

\section{$\mathbb{N}$}

UESTRO panorama del espíritu musical de Goethe sería incompleto si nos atuviéramos solamente al elemento pasivo: entender y comprender. Una naturaleza poderosa nada recibe que no restituya fecundado. Goethe, por donde pasa, crea. Mas, puesto que no era músico, sino poeta de oficio, ¿qué huella ha dejado la música en su creación poética? Una, por de pronto, que nos parece asombrosa, por la importancia que él le ha atribuído y por su tenacidad: su apasionada vocación de libretista musical. Verdaderamente se podría decir que este es su violín de Ingres (1). Le ha consagrado un número de horas

(1) Esta curiosa pasión por los libretos persiste en él hasta sus últimos años. En 1828 se entretenía rehaciendo el libreto de Moisés de Rossini. Hubiera querido rehacer su Tancredo y transformarlo en favola boscareccia. Un mes antes de su muerte, en Febrero de 1832, dicta un largo ensayo sobre los poemas de Jouy, libretista de Spontini. Se apasiona por los poemas de Haendel y no perdona a Weber lo de Euryanthe y Oberon. En esto, en perfecto acuerdo con Beethoven. Y para ambos el mejor poema de ópera es Le porteur d'eau de Cherubini.

Nunca ha querido juzgar una ópera independientemente del poema. El poema ante todo.

No os comprendo muchachos-escribe en 1828-: ¿cómo podéis separar el sujeto de la música y juzgarlos en sí a cada uno de ellos? ... Os admiro. ¿Cómo pueden escuchar vuestros oídos y saborear los sonidos, mientras que el principal sentido, el ojo está martirizado por el absurdo del sujeto?

(Hubiera podido decir, en vez del ojo, la razón; puesto que es a la razón a quien se dirige el sujeto de que se trata. Pero es un hecho que para Goethe el ojo es el órgano de la razón.)

Y dice bien. Pero la mayor parte de los músicos poseen poco ojo y much a menos razón. No se les puede reprochar por eso. ¡Que tengan grandes oídos! Pero nada les obliga a poner su música en óperas, es decir a martirizar el ojo y el buen sentido. Apruebo en absoluto a Goethe. Y estoy seguro de que Beethoven gritaría: ‘jbravo! s 